\title{
Apertura de rutas al Norte 1820-1860: La cuenca del río San Juan y la Guerra Nacional
}

\section{Opening of routes to the North 1820-1860: The San Juan river basin and the National War}

\author{
Jorge León Sáenz \\ Investigador independiente; San José, Costa Rica. \\ muleoni@ice.co.cr \\ https://orcid.org/0000-0003-0683-9221
}

Referencia/ reference:

León, J. (2021). Apertura de rutas al Norte 1820-1860: La cuenca del río San Juan y la Guerra Nacional. Yulök Revista de Innovación Académica, 5 (1), 36-55. https://doi.org/10.47633/yulk.v5i1.365

\section{Resumen}

El objetivo es analizar como nuevas rutas hacia la región norte de Costa Rica reflejaron intereses políticos y económicos del país y del istmo centroamericano a mediados del siglo XIX. La contribución del artículo reside en reconstruir sistemáticamente la historia y la ubicación de rutas al norte, en función de cómo dieron respuesta a dichos intereses. Se recurrió a fuentes impresas, documentos, mapas y periódicos. La posición de Costa Rica en el istmo centroamericano facilitó su participación en el comercio mundial, pero su crecimiento hizo necesario explorar nuevas rutas por los ríos Sarapiquí y San Carlos para comunicar el Valle Central con el puerto de San Juan Norte en el Caribe. Estas rutas al norte, fueron indispensables para mantener la soberanía del país durante la Guerra Nacional, el control del San Juan, la derrota a los filibusteros y la negociación del tratado fronterizo con Nicaragua. Finalmente, se sentaron las bases para la posterior colonización de la región norte.

Palabras clave: Centroamérica, Geopolítica, Relaciones económicas internacionales, Historia económica, Transporte.

\section{Abstract}

The purpose of the analysis is on how new routes to the northern region of Costa Rica reflected national and Central American political and economic interests in the mid XIX century. A specific contribution was a historical and locational reconstruction of the routes to the north, in response to the said interests. Sources utilized included printed works, documents, maps and newspapers. Costa Rica's position on the Central American Isthmus, facilitated its participation in world commerce, but its growth made it necessary to explore new routes through the Sarapiquí and San Carlos rivers, to the port of San Juan Norte on the Caribbean. These routes enabled the country to maintain its sovereignty during the Guerra Nacional, by controlling the San Juan river and Lake Nicaragua, crucial to the defeat of the filibusters occupying Nicaragua, and valuable while negotiating the boundary treaty with Nicaragua. Finally, these roads were fundamental to the colonization of the northern region decades later.

Keywords: Central America, Geopolitics, International economic relations, Economic history, Transport. 


\section{Introducción}

La posición geográfica de Costa Rica, al estar ubicada en un istmo, es sumamente privilegiada, ya que esta situación dio al país acceso a los dos principales océanos y por tanto al mundo exterior, facilitando el comercio, los viajes de ciudadanos a otros países y la llegada de inmigrantes, aspectos fundamentales que han moldeado el ser costarricense. Debido a su ubicación, el istmo centroamericano también fue, a partir del siglo XVI y hasta el presente, una zona focal de interés geopolítico, donde grandes potencias han tratado de establecer un dominio sobre el paso del istmo, con la finalidad de ejercer control del comercio mundial que pasa por este.

Este estudio está dirigido a analizar dos elementos: los intereses políticos y económicos principalmente de Costa Rica y de Nicaragua, respecto a la porción del istmo centroamericano que comparten, y segundo, aquellos aspectos de intereses geopolíticos contrapuestos de potencias extra regionales y como ambos incidieron sobre los acontecimientos históricos que se analizan para el período 1820-1860. Considerar conjuntamente las dimensiones nacional-regional-geopolítica y su impacto sobre una subregión del país en ese periodo, permite introducir una visión integrada sobre el proceso de ocupación inicial del territorio, el cual sentó bases para el desarrollo posterior de la región norte del país. Permite también mostrar, como la geografía de la zona incidió para facilitar al país enfrentar con éxito, un momento crítico de su historia, debido a la intervención de intereses externos que pusieron en riesgo su soberanía.

El método de análisis se construyó primero con base en la revisión y cotejo de documentación histórica, incluye estudios sobre relaciones exteriores y sobre la Guerra Nacional, relatos de viajeros y documentos de la época del Archivo Nacional, para efectos de presentar el contexto histórico. Estos fueron complementados con información geográfica, incluidos estudios descriptivos de la cuenca y las subregiones de Sarapiquí y San Carlos, mapas y otros, con el propósito de formar mapas que dieran sustento al contexto físico y a las rutas y las modalidades de transporte existentes. Finalmente, se hizo uso de datos estadísticos sobre población, aduanas y otros, para caracterizar el proceso de desarrollo histórico a lo interno de la región norte.

Inicia con la descripción del área geográfica, para dar a conocer los principales elementos como ríos, lagos, mon- tañas y planicies donde se desarrollan los principales hechos históricos de alcance nacional o regional. Ubicados los hechos de mayor importancia, y los factores geopolíticos externos que incidieron sobre el istmo centroamericano, se pasa a presentar una discusión del proceso de exploración de las rutas al norte y el papel que tuvieron en los hechos bélicos ocurridos en 1855-1857 y finalmente sobre su influencia en la negociación de la frontera norte.

\section{Antecedentes}

La cuenca del río San Juan: aspectos geográficos básicos

La margen sur del río San Juan forma actualmente la parte más importante de la frontera entre Nicaragua y Costa Rica, parte desde la desembocadura del río en San Juan Norte sobre el mar Caribe, hasta unos 5 kilómetros antes del Castillo de San Juan, a partir de donde la frontera corre en una línea paralela al río y luego al Lago de Nicaragua, retirada unos 3 kilómetros de ambos. El lago y el río, con los afluentes que caen en estos, hacen la denominada cuenca del Río San Juan, que cubre una enorme extensión de más de $40.000 \mathrm{Km}^{2}$ (dos veces el territorio de El Salvador), de los cuales $30.000 \mathrm{Km}^{2}(70 \%)$ corresponden a Nicaragua y casi $12.000 \mathrm{Km}^{2}(30 \%)$ a Costa Rica. En términos de habitantes, un $57 \%$ de la población nicaragüense vive en la cuenca, OEA (2004), mientras que, en Costa Rica, la región Norte del país que se ubica en la cuenca, representa un $8 \%$ de la población costarricense, León y Mora (2018).

Los elementos geográficos que caracterizan a la cuenca son: por el norte, el enorme Lago de Nicaragua (8.000 $\mathrm{Km}^{2}$ ) y el río San Juan, con una longitud de 205 kilómetros desde el lago hasta su desembocadura. Por el sur, están los principales afluentes del San Juan, provenientes principalmente de Costa Rica como los ríos Frío, Pocosol, San Carlos, Sarapiquí y Chirripó y el río Colorado, el cual es más bien un ramal del San Juan, pero que se separa del cauce para salir directamente al mar. Ver Figura 1.

Son el río San Juan y sus afluentes, la parte de la cuenca sobre la cual se va a concentrar este trabajo. (ver figura 1). Dado que la región norte queda delimitada al sur por las cordilleras volcánicas Central y de Guanacaste, que corresponden a la zona de mayor altura (desde los 500 metros hasta unos 2.800 metros en el volcán Poás), se presenta aquí una topografía muy quebrada, cortada por muchos ríos, producto de la alta precipitación. Esta zona 


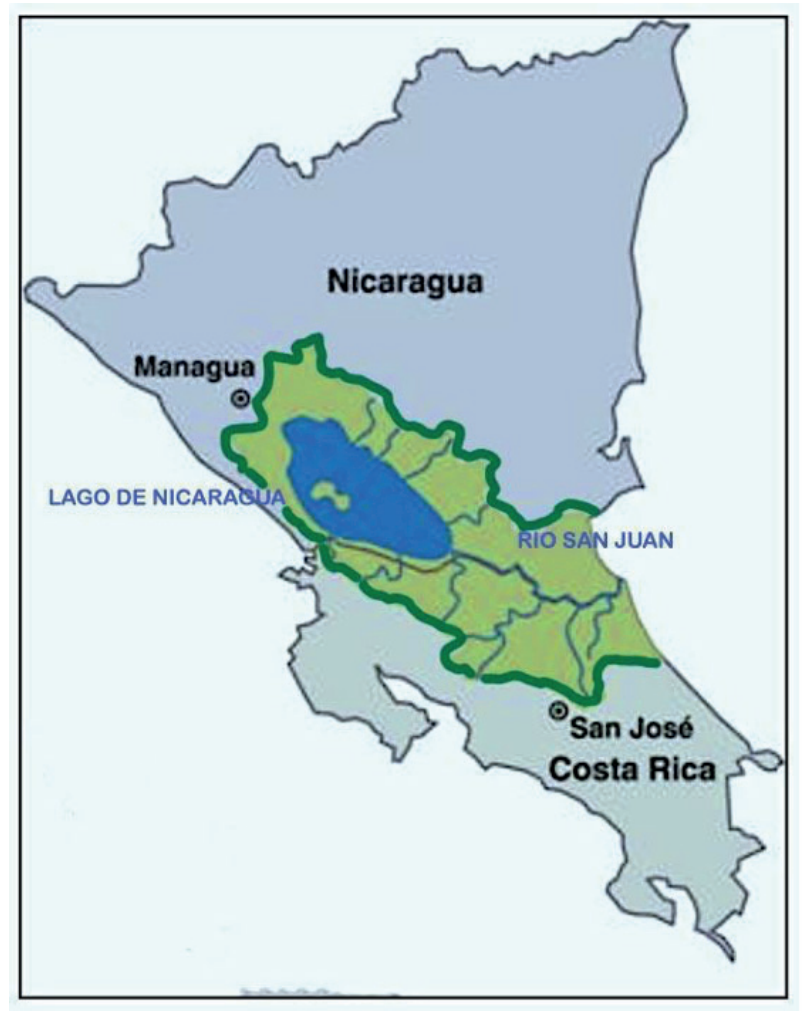

Figura 1. La cuenca del río San Juan. Fuente: Hispagua.cedex. es cuenca binacional San Juan.

alta cubierta por bosques fue el obstáculo principal que encontraron los costarricenses durante el siglo XIX para penetrar a la región Norte desde el Valle Central, la región más poblada del país. Por el contrario, desde Nicaragua al norte, se encontró un acceso relativamente más fácil utilizando el Lago y el río San Juan para llegar a la costa del Caribe, así como para que algunos colonos se establecieran en los márgenes de ese río, e incluso penetraran por los ríos Frío y San Carlos.

\section{Antecedentes históricos}

Fue España, la primera potencia que reclamó para sí este territorio, como resultado del cuarto viaje de Cristóbal Colón en 1502, quien recorrió la costa de Centroamérica por el Caribe, pero sin percatarse de que había descubierto un istmo. Esto sucedió hasta 1513, cuando Vasco Núñez de Balboa cruzó Panamá y “descubrió" el Pacífico, lo que demostró que este era un istmo, una estrecha faja de tierra que separaba por poca distancia a ese océano del mar Caribe y del Atlántico.

Por la particular posición de Panamá que se extiende de este a oeste en el istmo, los españoles designaron al Pacífico recién descubierto como el Mar del Sur, mientras en contraste, se denominó Mar del Norte, aquel que bañaba la costa norte de Panamá. Dichos nombres se mantuvieron durante la época colonial, y no fue sino durante el siglo XIX que se hizo común el uso de Pacífico y Caribe o Atlántico para los dos océanos. Por esto, en Costa Rica durante las primeras décadas de la república, todavía se hacía referencia a la costa norte y al Mar del Norte, razón por la cual se mantendrán esos nombres en este trabajo.

La población costarricense estaba predominantemente situada en el Valle Central, desde la época colonial, pero desarrolló tempranos vínculos con el Caribe o Mar del Norte. Esto ocurrió tanto para establecer una ruta de comercio con Cartagena, Panamá y las islas Antillas, como después de 1600, para explotar el cacao al formarse plantaciones de este fruto en el Valle de Matina, vecinas a la costa. El cacao fue, en este y el siguiente siglo, uno de los principales productos de exportación. Esto hizo necesario abrir un camino de mulas de Matina a Cartago -donde vivían los dueños de plantaciones y los comerciantes que compraban ese cacao -para exportar a Centroamérica y en ocasiones hasta España. La ruta seguida por este camino fue siempre peligrosa y siendo no más que un sendero, no permitía trasegar grandes volúmenes de productos, sin embargo, el mismo fue utilizado por unos 250 años, indicando su importancia en el periodo colonial.

Con la llegada de la independencia, las llanuras al norte de la Cordillera Volcánica Central volvieron a cobrar interés tanto a particulares como al nuevo estado de Costa Rica. El nuevo estado promovió la producción y exportación de nuevos productos al mercado mundial, y buscó establecer una ruta hacia el río San Juan y el Caribe, como vía alterna al viejo camino de mulas de Cartago a Matina. Se emitieron así varios decretos del gobierno para estimular expediciones que encontraran una ruta al Norte y se otorgaron premios a los exploradores que las llevaran a cabo, por lo cual entre 1820 y 1830 se realizaron varias expediciones particulares a esta zona con ese fin.

Además de razones de índole comercial, surgieron otras relativas a la soberanía del territorio, al surgir reclamos respecto a dónde estaba la frontera, las cuales causaron constantes roces entre los dos nuevos estados de Nicaragua y Costa Rica. Sin duda, la realización de exploraciones al norte tenía como segunda intención afianzar los reclamos ante Nicaragua.

La apertura comercial posterior a la independencia se basó en la aceptación de una política de libre comercio 
entre los países americanos y entre estos y las potencias europeas y EE. UU., la nueva potencia regional que se encontraba entonces en plena expansión territorial y comercial. Costa Rica comenzó exportando tabaco, palo de Brasil, cacao y azúcar en pequeñas cantidades en las décadas de 1820-1830, pero fue cuando surgió el café como producto de gran potencial exportable a finales de la década de 1830, que surgió la necesidad de preocuparse por buscar mejores puertos y comunicaciones desde el Valle Central a aquellos. Un primer aspecto que requería mejorar eran las comunicaciones con el exterior, ya que estas se realizaban principalmente por el Pacífico, donde se canalizaba la gran mayoría del comercio, así como los pasajeros al exterior y la correspondencia, a través de barcos que traían mercadería y sacaban las exportaciones por Puntarenas. Hacia 1833, un hecho importante ocurrió cuando barcos-correo ingleses comenzaron a tocar en el puerto de San Juan del Norte en Nicaragua. Desde 1764, España había establecido los correos marítimos de Europa a las Indias, pero las revoluciones e independencia acabaron con ese sistema hacia 1820. Las comunicaciones vía correo continuaron utilizando barcos mercantes, pero su lento recorrido hacía poco fiable la comunicación. Por ello cuando Inglaterra asumió el puesto de principal potencia y estableció su propio sistema de correo, este fue el adoptado por todos los países del hemisferio occidental, León (1997, pp. 207-208).

Se generó interés por vincularse con ese sistema, debido a que permitía transportar correo y pasaje a Europa, al Caribe y a EE. UU. con mucho mayor rapidez y seguridad que por la ruta del Pacífico. El Bachiller Osejo en un viaje a Jamaica avanzó las negociaciones para concretar esa comunicación con el correo británico, Zelaya (1971, pp. 383-387), pero las autoridades inglesas en ese momento no aceptaron establecer el servicio.

La continua necesidad de una comunicación más expedita con el exterior durante la década de 1830 impulsó a la Anglo-Costa Rican Mining Co., empresa que a finales de esa década explotaba minas de oro en los Montes del Aguacate, a establecer de su cuenta un sistema de correo, con mensajeros propios que de las minas conducían correspondencia (¿y probablemente oro?) hasta San Juan Norte. Usaron estos un sendero al río Sarapiquí, y luego en bote continuaban a San Juan Norte, donde esa correspondencia era recogida por barcos postales ingleses, y conducida a Jamaica, a Inglaterra, Europa y a EE. UU. (Frantzius 1862 en Zeledón 1997, p. 81).
Sin embargo, como se indicó, la oportunidad real para que el país pudiera abrirse al mundo de manera más amplia, se presentó con el desarrollo del café como producto de exportación a Europa. Cuando a finales de los años treinta e inicios de los cuarenta del siglo XIX se dio un fuerte crecimiento los envíos al exterior del grano, las exportaciones se dirigieron a mercados europeos por el puerto de Puntarenas en el Pacífico. En cambio, muy poco del volumen de café exportado fue dirigido a puertos del Caribe, a pesar de la mayor cercanía de esos a los mercados de Europa. En un principio el café exportado por el Pacífico fue enviado a Valparaíso y de allí re-exportado a Europa. Cuando a partir de 1839, barcos ingleses iniciaron el transporte de café directo a Europa, se evitó así a los intermediarios anglo-chilenos, pero esto hizo necesario que los exportadores nacionales se comunicaran de forma constante con los consignatarios de café ubicados en Londres, para dar o recibir instrucciones de compra y venta del grano. Mientras los sacos de café embarcados en Puntarenas tomaban en promedio unos 110 a 120 días en viaje directo a Londres, León (1997, p. 259), el correo marítimo hacía el mismo recorrido en solo 30 a 35 días, Seija-Riitta (2006, p. 177), esto permitía que una vez despachado el café en el puerto, el exportador podía enviar comunicaciones para negociar su venta, mucho antes de que el cargamento arribara al mercado en Londres, o incluso tenía oportunidad de conocer las condiciones del mercado previo a la llegada del embarque.

Como el transporte marítimo del café se realizaba principalmente en buques de vela por la ruta del Pacífico que daban vuelta por el Cabo de Hornos, el país dio prioridad a construir entre 1843 y 1845 un camino de carretas a la costa pacífica, que se conoció como la Carretera Nacional. Su construcción representó el abandono del viejo camino colonial de mulas entre el Valle Central y la costa del Caribe. Si bien el Estado en su concesión de la Carretera a la Sociedad Económica Itineraria, también encargó a esta, construir un camino al Caribe, dicha actividad fue atendida solo de manera secundaria.

Aunque al Caribe solo se contaba con el viejo camino de mulas a Matina, los comerciantes nacionales importadores de bienes habían establecido en los años treinta, nexos con Jamaica y los productos enviados de allí, los cuales en volúmenes cada vez mayores, ingresaban por los puertos de Matina y de Moín. Había por tanto un estímulo para la economía nacional de construir una carretera al Caribe y entre 1838 y 1839 se contrató con un topógrafo, Enrique Cooper, para levantar un informe y 
un mapa para esta posible ruta, Cooper (1896). Sin embargo, las dificultades técnicas de construir esa siguiendo el camino de mulas a Matina se hicieron manifiestas con estos estudios. Por ello, surgieron otras iniciativas dirigidas a buscar más bien una salida al Caribe por el río San Juan, concretamente por el puerto de San Juan Norte o Greytown como lo denominaban los anglosajones. Para 1840 , ya el sistema de correo inglés había establecido una comunicación semanal regular entre ese puerto y el de Chagres en Panamá, de donde seguía la ruta a Jamaica y luego a Europa. Esta situación volvió muy atractiva de nuevo la búsqueda de una ruta al Caribe, pero esta vez en dirección norte, cruzando la cordillera volcánica y las llanuras de Santa Clara para llegar al San Juan. Por esta ruta, los ríos constituían una modalidad de transporte fundamental, pues de los 178 kilómetros entre San José y San Juan Norte, el 40\% se hacía por los ríos Sarapiquí y San Juan, Molina (1851).

\section{Factores geopolíticos}

La expansión territorial de los EE. UU. se aceleró a partir de 1820 y se introdujo como un riesgo cada vez mayor para los países latinoamericanos, en particular para México y Centroamérica. No contentos con el territorio obtenido a raíz de la revolución que culminó en 1776, durante los siguientes 70 años la nueva potencia continental adquirió enormes extensiones - primero de Francia, el territorio de Luisiana en 1803, seguido por la compra de Florida a España (1817), con lo que duplicó así su tamaño. En 1823 la llamada Doctrina Monroe, se emitió con el propósito de excluir de América en adelante a las potencias europeas. Entretenidos por dos décadas en llenar estos vastos espacios, y en la eliminación de las tribus indígenas que los habitaron, luego emprendieron una segunda ola de expansión. Primero, colonos estadounidenses establecidos en Tejas, quienes después de un tiempo se rebelaron contra México y en 1845 se unieron a EE. UU., mientras en 1846 por negociaciones con Gran Bretaña, las dos potencias se dividieron en la costa noroeste de Norteamérica, con los EE. UU. recibiendo el enorme territorio de Oregon, que se extendía al sur del paralelo 48 norte hasta California. Finalmente, en 1846-1848 los EE. UU. hicieron la guerra con México, al despojar California y Nuevo México, Robertson, (1964, pp. 100-101).

Era claro entonces, que el imperialismo de la nueva potencia, podría llevarla a Centroamérica. De hecho, desde 1835 el Congreso de EE. UU. había ordenado la exploración de una ruta a través del Istmo Centroamericano y en la década de 1840 , comenzaron sus diplomáticos a combatir los intereses ingleses en el istmo. Estos ejercieron una dominación económica a través del comercio exterior, pero sin hacer una ocupación del territorio.

El control del istmo con la finalidad de construir una ruta a través de este se convirtió en un asunto de estado, que produjo una fuerte rivalidad entre EE. UU. y Gran Bretaña, la cual, en ocasiones, tuvo amago de convertirse en una guerra. Sin embargo, los ingleses entendieron que sus principales intereses estaban en la Asia y no tanto de enfrentarse en América con los EE. UU., por lo que estuvieron anuentes a un arreglo político, con la firma en 1850 del tratado Clayton-Bulwer. En este las dos partes acordaron - sin consentimiento de las naciones centroamericanas directamente involucradas - que la eventual construcción de un canal por parte de uno de ellos no podía ser realizado sin el consentimiento de la otra parte. Este tratado impidió por los siguientes 50 años, que el Gobierno de los EE. UU. pudiera participar en construir el canal.

Dos hechos externos nuevos complicaron el panorama para Centroamérica: el primero fue la ola migratoria masiva que generó el hallazgo de oro en California en 1848, ola que pasó del este de EE. UU. al oeste por vía de Panamá y Nicaragua, convirtiendo a ambos en áreas de interés geopolítico. El segundo, fueron disputas internas en EE. UU. al intentarse abolir la esclavitud en todos los nuevos territorios adquiridos, lo que años después llevaría a la guerra civil en ese país. El primer asunto se resolvió por la intervención en ambos países de inversionistas privados estadounidenses; estos construyeron un ferrocarril en Panamá (1851-1855) y establecieron desde 1851 la comunicación por el río San Juan y lago en Nicaragua, utilizando vapores fluviales. Empresas marítimas de EE. UU. establecieron las rutas entre ese país y los puertos centroamericanos, apoyados por contratos de correo del gobierno estadounidense. En ambos casos, los sistemas de transporte se obtuvieron de los gobiernos de Nueva Granada y Nicaragua por concesiones de largo plazo, a cambio de pingües pagos por el paso y con mínima participación de los ciudadanos de ambos en los beneficios, que fueron acaparados por extranjeros.

En 1850 la American Atlantic \& Pacific Steamship and Canal Company, obtuvo del gobierno de Nicaragua, los derechos de explotar la ruta del istmo que utilizaba el río San Juan y el Lago de Nicaragua. Esta empresa fue establecida por empresarios estadounidenses, entre los cuales 
destacaba el Comodoro Cornelius Vanderbilt, quien era uno de los más destacados transportistas marítimos de la época. Rápidamente la empresa se organizó para realizar el transporte de miles de viajeros en barcos de vapor, desde Nueva York y Nueva Orleans a San Juan Norte. En este puerto eran trasladados a pequeños vapores de río, para recorrer el río San Juan y el Lago de Nicaragua, cruzando luego los pasajeros el último trayecto de unos 20 kilómetros por tierra hasta San Juan Sur. Aquí, la empresa los embarcaba de nuevo en vapores para hacer el recorrido final hasta California. La porción del viaje dentro de Nicaragua estaba a cargo de la Compañía Accesoria del Tránsito (CAT), subsidiaria de la Atlantic $\&$ Pacific. El tráfico sobre esta ruta fue en fuerte aumento puesto que mientras en 1851 sólo lo utilizaron unos 1.300 pasajeros, en promedio en cada uno de los años siguientes de 1852 a 1855, pasaron por el Tránsito unos 12.000 pasajeros, es decir casi 10 veces más. La vía por Nicaragua rivalizó con la ruta a través del istmo de Panamá, pero aquella predominó al llevar casi dos tercios de los viajeros a California entre 1848 y 1855 . El negocio en todo caso de la CAT era boyante, hasta que la guerra contra los filibusteros produjo primero su reducción y luego total suspensión, Folkman (1993, p. 166, apéndice B). En 1856, primer año de la guerra, pasaron solo 6.092 pasajeros y en 1857, 1.443; de 1858 a 1861, la ruta estuvo totalmente cerrada y solo logró recomenzar en 1862 hasta 1868 cuando cesó del todo operaciones.

El segundo aspecto, el expansionismo estadounidense resultó aún menos favorable para los centroamericanos, pues llevó a la incursión en la región de filibusteros provenientes de EE. UU., siendo lo más notorio, la incursión de los filibusteros y la toma del gobierno de Nicaragua por William Walker entre 1855-1857, lo cual obligó a la región a realizar la Guerra Nacional para liberarse del dominio que planteaban establecer los invasores.

Producto de una prolongada guerra civil en Nicaragua (1854-1855), entre legitimistas (Granada) y demócratas (León), hizo que los segundos negociaran el ingreso a ese país de filibusteros, para que a manera de mercenarios les ayudaran a obtener el poder, bajo el disfraz de un contrato de colonización de extranjeros. Gradualmente, William Walker, el jefe de los filibusteros se hizo con el poder en ese país, levantando las alarmas en los países centroamericanos, en particular en Costa Rica, cuyo gobierno venía siguiendo de cerca los acontecimientos en la región, incluyendo el interés demostrado por los EE. UU. en llegar a controlar el istmo. Así, desde 1854, se tomaron medidas dirigidas a afrontar este reto, tanto en el campo diplomático como militar, recurriendo al fortalecimiento de los lazos con Gran Bretaña y con Francia, naciones que rivalizaban en el istmo con los EE. UU. En dichos países, los cónsules respectivos de Costa Rica, Eduardo Wallerstein y Gabriel Lafond, tuvieron éxito en comunicar la posición nacional a los Ministros de Relaciones Exteriores inglés y francés, y así obtener el apoyo diplomático para Costa Rica. El primero de ellos, Wallerstein, no solo logró ese apoyo inglés, sino que logró obtener armas para el ejército, las cuales llegaron a Puntarenas en barcos que venían a cargar café a inicios de 1855, León (1997, p. 124), es decir con suficiente anticipación al inicio de actividades bélicas. Cuando comenzó la guerra a inicios de 1856, ambos cónsules, de nuevo solicitaron el apoyo inglés y francés, para prevenir que los filibusteros interfirieran en el comercio del país y en el tráfico de pasajeros y correo. Mientras tanto Felipe Molina, el ministro de Costa Rica ante EE. UU., realizó ingentes esfuerzos ante el gobierno estadounidense desde 1855, para informar sobre la situación y buscar contrarrestar a políticos de ese país que apoyaban a los filibusteros.

Un tercer factor, en este caso solo de carácter regional, que vino a agravar las relaciones exteriores de Costa Rica con Nicaragua, fue el hecho ya mencionado que existía un fuerte diferendo entre ambos países, respecto a la delimitación de la frontera común. Durante la época colonial al pertenecer todos los estados centroamericanos al imperio español, no había sido necesario establecer fronteras muy definidas, especialmente en las zonas menos pobladas y remotas. Sin embargo, una vez declarada la independencia, aparecieron los primeros problemas. Por motivos políticos ocurrió en 1824 la anexión del Partido de Nicoya, antes dependiente de Nicaragua, a Costa Rica. Esto representó un primer punto de discordia entre los dos países; y el reconocimiento por la Asamblea de la República Federal de Centroamérica de la anexión en 1825, no resolvió la disputa. Cuando la Federación dio visos de resquebrajarse en 1838, el asunto de definir fronteras entre los Estados volvió a tomar importancia, Obregón (1984, pp. 115-116).

Además, en la década de 1840, un fuerte aumento en el comercio externo llevó a Costa Rica a buscar una salida alterna a la del Pacífico vía el Cabo de Hornos para colocar sus productos en los mercados ubicados en el Atlántico. Entonces, surgió la propuesta de construir un camino al norte utilizando el río Sarapiquí, para lo cual era necesario proponer a Nicaragua el uso conjunto del 
puerto de San Juan del Norte. Ese país, que se encontraba en una enconada lucha con Gran Bretaña por el control de la Mosquitia y del puerto de San Juan o Greytown como lo denominaban los ingleses, encontró ofensiva la propuesta, la rechazó y las relaciones se deterioraron. La posición de Nicaragua era que históricamente toda la cuenca del Lago y del río le pertenecían, y ante la posibilidad de construirse un canal interoceánico, no pretendía compartir los derechos de ese con Costa Rica. En 1848 una misión diplomática al vecino país, liderada por Felipe Molina llevó propuestas para fijar los límites, pero como el planteo por parte de Costa Rica era que los límites arrancaran en el río La Flor en el oeste y siguieran la margen sur del Lago y luego el río San Juan hasta desembocar en el Caribe, este fue rechazado por Nicaragua. Los mapas de Nicaragua de von Bulow 1849, Baily 1850, Squier 1851 y Ferrer 1856, todos mostraban la frontera con Costa Rica a partir del río de La Flor, pasando muy al sur del Lago y el río San Juan, hasta llegar al río Sarapiquí, siguiendo por este río al San Juan y por este último hasta la desembocadura, es decir una línea muy al sur de la que reclamaba Costa Rica. Ver: von Bulow (1849), Aguirre (2002).

El papel de las rutas terrestres y fluviales en cuanto a la apertura de la región norte del país y sus consecuencias históricas, políticas y económicas, con un enfoque integral, ha sido analizado para diferentes épocas en Frantzius (1862), González (1976) y Girot (1989). Resalta en estos la importancia de las vías de comunicación para la apertura en el largo plazo de la región norte y la consolidación de la soberanía nacional sobre esta.

\section{Apertura de la ruta al Norte: Un proceso lar- go y difícil}

Como se mostró en la sección anterior, múltiples factores geográficos e históricos incidieron para focalizar el interés sobre la cuenca del río San Juan, no solo de los dos países que forman dicha cuenca, sino que también atrajeron la atención de potencias extranjeras, por motivos geopolíticos. Esta sección se enfoca en cómo reaccionaron estos diversos intereses, ante los cambios que se dieron entre 1820 y 1860 , primero en cuanto a las relaciones políticas y económicas, cuál fue el efecto de estas en el territorio, en particular en Costa Rica, y finalmente como el escaso desarrollo de la zona hasta mediados del siglo XIX influenció los resultados de la segunda etapa de la Campaña Nacional.
Como fue señalado, Costa Rica contaba desde la época colonial, con un camino muy precario al Caribe que llegaba hasta Matina, y que, a inicios del siglo XIX, fue prolongado hasta Moín, debido a que este era un puerto más seguro. Se convirtió entonces Moín en el puerto de entrada y salida del limitado comercio que realizaba Costa Rica por el Caribe en las décadas de 1820-1830. La necesidad de un mejor camino al Mar del Norte surgió más adelante, cuando el auge en la exportación de café a Europa hizo crecer el tráfico de importación por Moín, de bienes provenientes de Europa vía Jamaica, y ocasionalmente de EE. UU. Es de anotar, que estudios sobre el comercio exterior del país antes de 1850, casi no mencionan este movimiento comercial, Molina (1851, p. 36-37), León (1997, pp. 57-61). La importancia real alcanzada por esa ruta, sin embargo, indica que entre 1839 y 1843 en promedio un $38 \%$ de las importaciones del país ingresaba por esa vía, ANCR Hacienda 17469, 249966658. Se estableció una aduana en Matina, donde se recibían los bienes desembarcados en Moín, pero las dificultades de la ruta hacían muy caro y largo el transporte. En 1842 los fletes terrestres de Puntarenas en el Pacífico a San José eran de entre $\$ 0,95$ (verano) y $\$ 1.25$ (invierno) por carga de 125 libras, mientras que de Matina a San José era de $\$ 1.50$ por fardo, es decir costaba cerca de $50 \%$ más enviar carga por el Caribe, Sáenz Maroto (1970, pp. 577-578) y Zelaya (1971, p. 350). Además, en estos años, el tiempo de viaje a Puntarenas era de unos 4 o 5 días, mientras que era de 15 días a Matina. El gobierno debió entonces realizar varias acciones para buscar redireccionar el comercio a través de una nueva salida al Mar del Norte (Caribe), como se analizará más adelante.

\section{Nicaragua y el río San Juan}

Mientras en la década de 1820, del lado costarricense de la cuenca continuaba siendo aún un sueño llegar al río San Juan por el sur, del lado de Nicaragua la situación era diferente. En una breve descripción de Nicaragua, el último gobernador español, Miguel González Saravia (1817-1821), señalaba que “...el comercio por el mar del Norte es más valioso y productivo que el que se hace por el Sur..." y ese comercio se realizaba por el lago de Nicaragua y el río San Juan, hasta San Juan Norte. San Juan Norte mantenía un tráfico regular en las primeras décadas del siglo XIX con Cartagena y La Habana, así como un comercio de contrabando con los ingleses en la Mosquitia y en Jamaica. Ver Roberts (1965). González, advertía que el llamado puerto de San Juan Norte en la época de su gobierno, a pesar de ser un buen fondeadero, 
se encontraba deshabitado excepto por un destacamento militar encargado de vigilar y avisar de la llegada de barcos mercantes que venían a llevar o traer productos, o proteger de las incursiones de indios misquitos que aún tenía lugar. (González Saravia, 1823, en Arellano, 2005, pp. 23, 30-31). De manera perspicaz, este gobernador se refirió a San Juan Norte como:

... objeto preminente para la prosperidad y riqueza de la provincia entera ... si ha de figurar con importancia política, mercantil y opulencia y que jamás acertaremos ... a recomendarle bastantemente a sus patrióticos habitantes. Ellos y los de Costa Rica tienen un interés común en esta parte, pues el año de 1821 se descubrió un brevísimo camino desde la ciudad de San José de Costa Rica al Río San Juan, entrando en él por el Sarapiquí... (González Saravia, 1823, en Arellano, 2005, pp. 31-32).

El comercio de Nicaragua y en particular el de Granada se realizaba por medio de botes llamados bongos, que navegaban a vela por el Lago y a remo por el río San Juan, cada uno con una capacidad de hasta 10 a 15 toneladas, y duraban unos 8 días en el viaje al mar y 10 días en el retorno. Sin embargo, el llamado puerto de San Juan Norte seguía casi sin población una década después de la descripción de González, pues otro viajero, en 1832, señalaba que sólo existía allí la casa de un comerciante inglés y el destacamento militar ya mencionado, (Haefkens 1832, en Arellano, 2005, pp. 51-52). Y es que, a lo largo de los 140 kilómetros de extensión del río entre San Juan del Norte y su salida en San Carlos en el Lago de Nicaragua, todavía en 1836-1837 otro explorador indicaba que el bosque impenetrable en cada margen resultaba en que, "...no hay aquí lugar alguno habitado y cultivado en ninguna parte, aunque el suelo tiene una fertilidad increíble...", (Baily 1848, en Arellano 2005, p. 96). Este ingeniero fue contratado por la Federación de Centroamérica para analizar la posibilidad de un canal a través de Nicaragua. El estudio lo realizó Baily entre 1836 y 1837.

A pesar de que por el sur de la cuenca no era aún posible un fácil acceso al río San Juan, por el lado nicaragüense, donde ya existía el movimiento de bongos entre San Juan Norte y Granada, comenzaba a asentarse población en sus orillas y en las cercanías del puerto, motivada por el movimiento comercial alcanzado. Fue entonces cuando por Nicaragua aumentó el uso de ríos navegables como el Sarapiquí, el San Carlos y el río Frío, que en esa época la población consideraba que formaban parte de su país.
La entrada por estos afluentes del San Juan permitió establecer una mayor explotación de productos del bosque en los llanos cruzados por esos ríos, como era el caso de madera, zarzaparrilla y hule. Un caso particular fue el de la empresa del francés A. Dumartray que obtuvo una concesión que utilizó desde 1829 hasta 1838 para establecer una plantación de caña entre Sarapiquí y Hacienda Vieja, con el propósito de abastecer a San Juan Norte con azúcar y aguardiente, aunque eventualmente el negocio fracasó debido a la escasez de mano de obra en la zona, Frantzius (1862, pp. 80-81). Los restos del trapiche de hierro de esta empresa todavía existían en la década de 1960 cuando fueron fotografiados (Colección Meléndez, CIHAC).

La condición de subdesarrollo de la región de San Juan Norte fue entonces cambiando a finales de la década de 1830 cuando el puerto comenzó a recibir un número mayor de barcos veleros con importaciones para Nicaragua y en menor medida para Costa Rica. Además, con el inicio de viajes regulares de barcos del servicio postal inglés en 1839 al puerto, la cantidad de correspondencia y pasajeros aumentó. En las siguientes dos décadas, San Juan Norte se convertiría en puerto libre y por añadidura en la terminal y sede de operaciones de la Compañía Accesoria del Tránsito, y de las líneas de vapores de Nueva York y Nueva Orleans. Los ingleses y sus aliados moscos ocupaban el territorio de la Mosquitia desde el siglo XVII, y extendieron su dominio a San Juan Norte, la cual denominaron Greytown. En 1850 declararon a este como puerto libre, es decir que los bienes transados por comerciantes allí radicados no pagarían en adelante derechos de aduana y las naves que arribaran solo pagarían derechos mínimos en el puerto. Estas condiciones privilegiadas, al eximir al comercio de impuestos, atrajo a muchos comerciantes extranjeros a San Juan Norte, y dio prosperidad a la población, que en 1851 se estimaba en cerca de mil personas, la mayor parte de origen europeo o estadounidense. Molina (1851, p. 53). A pesar de su estatus de puerto libre en 1854 Greytown fue bombardeado por un barco de guerra estadounidense, que lo destrozó completamente. En ese año, vapores de la Mala Real inglesa dos veces por mes hacían el servicio de correo y pasajeros para Southampton, Inglaterra; así como también dos veces al mes se recibían de Nueva York los vapores de la empresa Independent Line organizada por Vanderbilt, y cuyos pasajeros a California eran transbordados en San Juan Norte a los vapores de río de la Compañía del Tránsito.

En los años posteriores hasta el inicio de la Guerra Nacional en 1856, la mayor actividad del puerto provino del 
Tránsito, puesto que el movimiento a través de Nicaragua hacia California creció con rapidez como se señaló anteriormente. La CAT, a pesar de que la ruta por el río San Juan enfrentaba problemas por cuatro raudales que se encontraban a la altura del Castillo, que impedían el paso de sus vapores del río, logró establecer una logística adecuada para llevar a los pasajeros de y para California. El hecho de que la ruta obligaba a realizar el transbordo de pasajeros y carga en varios sitios, permitió que empresarios extranjeros y algunos nacionales ofrecieran servicios a los pasajeros que generaban ingresos a estos y daban empleo a muchos nacionales. El creciente nivel de actividad hizo que se comenzara a poblar las márgenes del río, para así suministrar leña a los vapores de la CAT, y hospedaje y alimentación a sus pasajeros. Por otra parte, los comerciantes mayores establecidos en Granada y en San Juan Norte, continuaron haciendo uso de los pequeños bongos quienes siguieron desempeñando una función importante para el comercio nicaragüense. Las exportaciones de Nicaragua, que en este periodo incluían añil, cueros, madera y otros, salían principalmente por este puerto el cual era también el principal en cuanto a importaciones.

\section{Exploraciones de la ruta de la parte costarricense}

Las reconocidas dificultades de la ruta a Matina motivaron que de parte costarricense se buscara una salida al Mar del Norte por otra dirección que no fuera la de Matina. Incluso antes de la Independencia, dos individuos realizaron exploraciones por su propia cuenta, pero buscando no al este hacia Matina, sino al norte, hacia Sarapiquí, que entonces era tierra completamente desconocida. El primero de ellos fue Eusebio Rodríguez, quien tendría en décadas posteriores una carrera distinguida como constructor de obras, y quien en 1819 hizo una primera entrada cruzando la Cordillera Volcánica, llegando hasta el río San José afluente del Sarapiquí. Un año después, en 1820, fue Joaquín Mora Fernández, hermano del futuro primer Jefe de Estado, Juan Mora Fernández., quien desde San José abrió una trocha por el Paso de la Palma para explorar el territorio al norte, y logró recorrer el Río Sarapiquí hasta su desembocadura en el Río San Juan, confirmando que existía una posible salida a ese puerto, (Frantzius, 1862 en Zeledón, 1997, pp. 7577). Sin embargo, la declaración de independencia y los incidentes políticos que la acompañaron, demoraron por un tiempo la continuación del apoyo del Estado para hallar una nueva ruta. Esto no significó que individuos con diversas motivaciones no buscaran seguir los pasos de
Rodríguez y Mora de encontrar una ruta al norte. Entre estos se señala a cazadores que en busca de presas atravesaron la Cordillera y llegaron a las planicies del norte; pero más importante, algunos viajeros urgidos de llegar a Europa hicieran lo mismo, siguiendo senderos abiertos. Existe documentación del viaje de un grupo de viajeros liderados por Richard Trevithick, quienes decidieron tomar el sendero al Sarapiquí en 1826 y lograron llegar a San Juan Norte, después de múltiples peripecias.

El interés en esa ruta se renovó en 1827 cuando el Gobierno, por Decreto CXIV, ofreció un premio de $\$ 500$ a quien encontrara una comunicación con el Mar del Norte. El primero, en tratar de obtener la recompensa, fue Miguel Alfaro, quien en 1826 había organizado una expedición al norte desde Alajuela pasando por el Paso del Desengaño, descendiendo hasta el río Toro Amarillo, un afluente del Sarapiquí, quien posteriormente volvió con mayores recursos en 1827, y alcanzó a descender por el Sarapiquí y llegar finalmente hasta San Juan Norte.

En seguimiento a los primeros intentos de los años 18201827 de abrir la región Norte, algunos inversionistas privados buscaron penetrar al norte para obtener tierras y el propio Gobierno emitió varios decretos para estimular a empresarios privados a emprender la apertura de la vía al norte por Sarapiquí. Un incentivo ofrecido a los inversionistas fue de compensar los gastos de las expediciones mediante la concesión de tierras, Anónimo, (1914, tomo I, p. 397). Así en 1835-1836, primero por Decreto CXXXI se ofrecieron hasta 1.000 caballerías de tierra a las compañías que abrieran caminos a Sarapiquí y Matina, cuya venta permitiría financiar los trabajos en los mismos. En 1836 por Decreto CLVI se mantuvo vigente la gracia ofrecida en 1827 de $\$ 1.000$ para aquel empresario que descubriera una vía de comunicación al puerto de San Juan del Norte, CLOD (1833-1836, p. 244-45; p. 318-319).

Después de las expediciones de reconocimiento antes mencionadas de la década de 1820, nuevas exploraciones fueron dirigidas por Pio Murillo en 1832 y 1833, interesado en colonizar las llanuras que veía desde la cima de la cordillera volcánica. Este abrió una vereda de Barva al Sarapiquí, la cual partía de Heredia, pasaba entre los volcanes Barva y Poás y siguiendo al norte, terminaba en la margen oeste del Río Sarapiquí, cerca del actual Puerto Viejo. Esa exploración dio a conocer las llanuras de Santa Clara y satisfacía el requerimiento de un camino para llegar a San Juan del Norte vía los ríos Sarapiquí y San

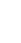


Juan, por lo que Murillo recibió una recompensa del Gobierno por su trabajo. Sin embargo, como el camino era solo para mulas, no era apto para el transporte de bienes pesados, por lo que su uso para el comercio fue limitado, ANCR (Fomento 1896) y Frantzius (1862, pp. 8283). Von Frantzius menciona que fue abandonado entre 1834 y 1847 , pero esto no parece ser cierto, pues algunos viajeros y el correo siguieron utilizándolo, aun cuando en 1835 el gobierno de Miguel Aguilar invirtió recursos para ampliar el ancho de la trocha hasta 8 varas en el trayecto desde el paso del Desengaño en la Cordillera, hasta San Miguel. A pesar de que no se contó con un camino propiamente en ese momento, a partir de 1835, pasajeros dirigidos a Europa y a las Islas del Caribe comenzaron a usar de manera regular la trocha al río Sarapiquí hasta el Muelle, donde seguían en bote hasta San Juan Norte, para tomar barcos que los llevaran a Cartagena o a Jamaica, y así seguir viaje al viejo continente, Frantzius (1862, pp.
77-79). Otros documentos registran que entre otros usaron esta trocha Antonio Pinto y Richard Trevithick entre 1827-1828.

Aunque la ruta hacia Sarapiquí fue la preferida por las autoridades, también se hicieron intentos de revivir la vía a Matina, siguiendo la brecha abierta en las montañas por el río Reventazón, por donde pasaba el antiguo camino de mulas. Así, cuando a mediados de la década de 1830 se creó el puesto de Director General de Caminos, se encargó un estudio más a fondo de la ruta existente, para lo cual se contrató en 1837 al topógrafo Enrique Cooper, para realizar un reconocimiento del camino a Matina y dar recomendaciones para su mejora. Cooper recomendó abandonar el viejo camino y construir una nueva vía que fuera directamente del Valle Central a Moín, la cual se separaba de la vía existente en Turrialba, para cruzar el río Reventazón y tomar su margen derecha, luego bajaría al

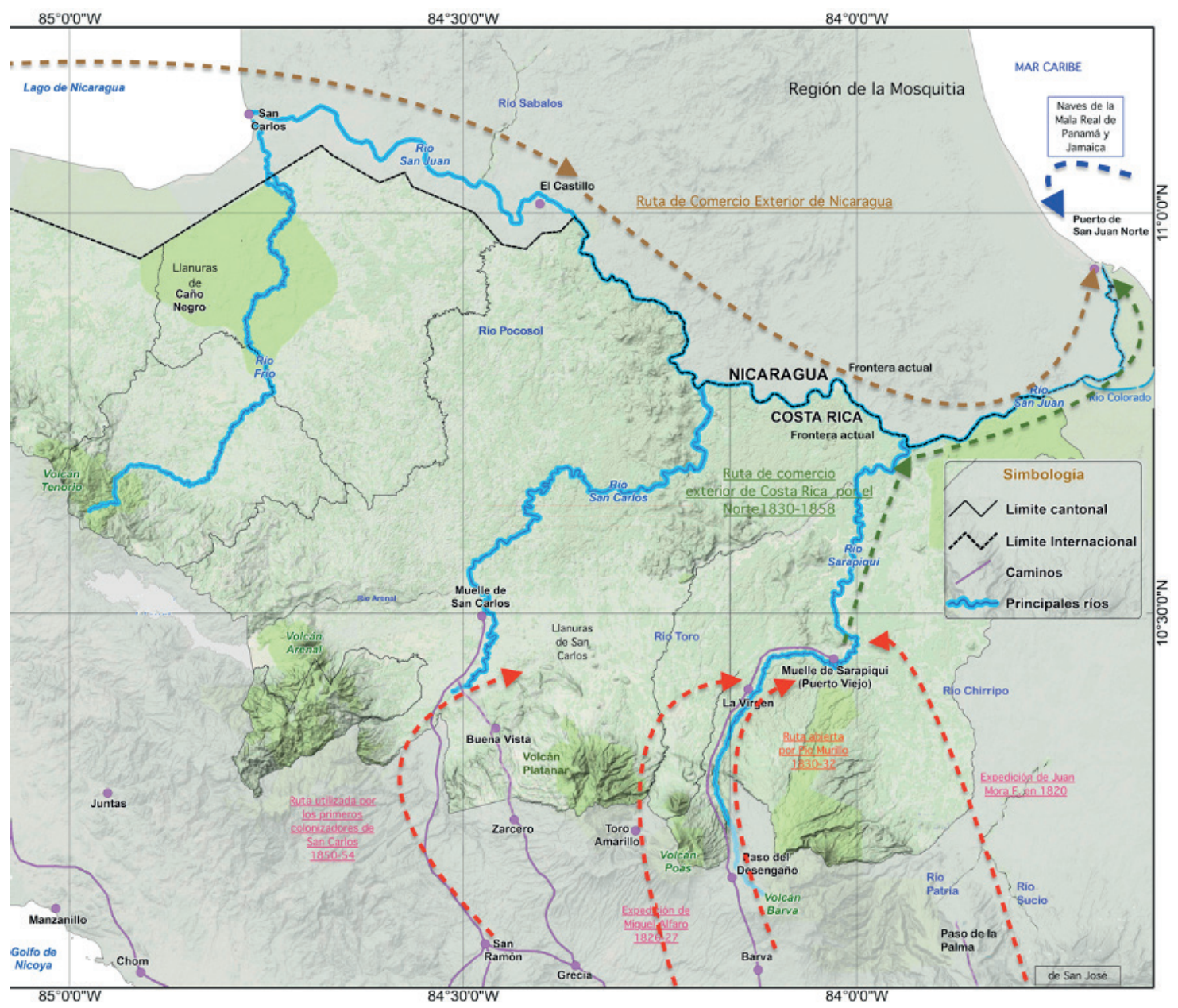

Figura 2. Las exploraciones y rutas seguidas para encontrar un camino al Norte 1820-1850. Elaboración propia sobre la base de León y Mora Proyecto (n.p. mapa 7.4) 
valle del río Pacuare, y al llegar este a la llanura atlántica, seguiría sobre el viejo camino hasta Moín, Cooper (1896, pp. 3-11). La magnitud del trabajo que representaba la propuesta de Cooper hizo desistir al gobierno de esta, y se optó más bien por realizar pequeñas mejoras en los años siguientes, por lo que el camino de mulas continuó estando en condición defectuosa, pero se mantuvo en uso durante la década de 1840, debido a requerimientos de los comerciantes para importar bienes por el Caribe.

Así las cosas, en los años de 1836 a 1841 el camino a Sarapiquí siguió en uso para el correo y algunos pasajeros, pero aún manejaba poca mercadería. En el caso del correo, la iniciativa de establecerlo por esta ruta la tomó la compañía minera Anglo-Costa Rican, mediante el viaje de un correo mensual que coincidía con el tráfico de vapores del correo inglés por San Juan Norte. Cuando cerró esa compañía, el Estado asumió el servicio de correo mensual a partir de 1842 y poco a poco incrementó el uso de la vereda, impulsado por el crecimiento del comercio y navegación por el puerto. Desde 1851 el correo a San Juan aumentó a una frecuencia quincenal, Frantzius (1862, p. 81).

La figura 2 señala de forma aproximada, la dirección tomada por las principales expediciones realizadas entre 1820 y 1850, en búsqueda del camino al Norte. Se observa que estas confluyen en la cuenca del río Sarapiquí, cerca del sitio denominado Muelle. El resto del viaje hasta San Juan Norte se realizaba en pequeños botes -bongos- que bajaban y subían por cauce del Sarapiquí, hasta la desembocadura de este en el San Juan, y luego seguían al río principal hasta el puerto.

Ante las continuas dificultades de la vía existente en Sarapiquí, entre 1846 y 1847 se realizaron nuevas exploraciones buscando una mejor ruta. La primera la realizó Manuel Alfaro, quien en 1826 había ya bordeado por el oeste al volcán Poas y bajado a la llanura siguiendo el curso del río Toro Amarillo; en esta ocasión fue mucho más al norte alcanzando el punto que este se volvía navegable antes de unirse al Sarapiquí poco antes de que ese desembocara en el San Juan, Frantzius (1862, pp. 86-87). Un año después, Luz Blanco quien había hecho un viaje a San Juan del Norte, exploró la vieja ruta de 1820 de Joaquín Mora, como mejor alternativa al camino a Sarapiquí. Descendió por el paso de La Palma y siguió el río Sucio hasta las llanuras de Santa Clara. En 1849 intentó establecer una finca ganadera allí, pero lo malo del camino lo obligó a renunciar y retirar el ganado. Se asoció con Pío
Murillo, para intentar reabrir el camino explorado por el segundo a Sarapiquí y así colonizar las llanuras de Santa Clara, pero el inicio de la Guerra Nacional contra los filibusteros en 1856 lo impidió, Frantzius (1862, pp. 83-84).

El gobierno bajo la administración Alfaro (1842-1844) aprobó a finales de 1843 la formación de la Sociedad Económica Itineraria para la construcción del camino de carretas a Puntarenas, también había encargado a esa la apertura de un camino al Atlántico. Sin embargo, como todos los recursos de la Sociedad se canalizaron al Camino Nacional, no pasó de realizar algunos pasos formales, el Estado decidió asumir la tarea de mejorar la ruta al norte. Una primera medida fue formar la Dirección de Caminos Generales, por Decreto 107 de mayo de 1848, Núñez (1924, p. 228), y asignarle la tarea de apertura de un camino carretero a las costas del Atlántico, siguiendo la ruta más conveniente. Por. Esa oficina realizó reconocimientos de la ruta por Sarapiquí y en 1848 presentó un informe en el cual mostraba en detalle las distancias horizontales y desniveles del camino desde el Muelle de Sarapiquí hasta la ciudad de Heredia, una medida fundamental para considerar la mejora del diseño de este. (ANCR, Fomento 3617).

El derrotero detallado Heredia-Sarapiquí fue publicado por el Ing. Ramón Minondo en El Costarricense No. 100, agosto (1848, pp. 556-557). La segunda acción significativa, fue la formación de la Compañía del Camino a Sarapiquí en 1851, la cual emprendió su trabajo. Se realizaron entonces inversiones importantes por primera vez y se terminó como camino carretero hasta la cuesta del Paso del Desengaño, además fue ampliado como camino de bestias hasta la cuesta de El Congo, entre Cariblanco y San Miguel en 1853, pero debido a problemas internos la Sociedad fue disuelta en 1855 , y se suspendió la construcción del resto del camino a Sarapiquí, ANCR, (Fomento 3888, 1673, 1681, 1683) y Frantzius (1862, pp. 81-82), aunque el estado continuó dando algún mantenimiento al mismo en los años siguientes.

La razón de mantener el abierto camino -aunque en mal estado- era que seguía siendo utilizado, tanto para pasajeros como para correo como se indicó, a partir de 1850 comenzó también a ser usado más para el comercio, aunque solo de importación de Costa Rica. Otra razón es que, al estar Nicaragua y Costa Rica involucrados en una pugna por fronteras, el tema de la construcción de un camino carretero hasta San Juan Norte era un arma que Costa Rica utilizaba en sus demandas, al proponer que debía 
considerarse al propio puerto de San Juan como de carácter bi-nacional e impulsaba esto como parte de los argumentos de reclamo territorial. Lógicamente Nicaragua no estaba de acuerdo con esas propuestas, y en 1848-1849 ambos países estuvieron a punto de entrar en un conflicto armado por el asunto de fronteras. Otro factor de conflicto era que cada país realizaba separadamente gestiones para atraer inversionistas interesados en la construcción de un posible canal a través del istmo utilizando el río San Juan y el Lago. Este tema es desarrollado en profundidad por Obregón (1984, pp. 173-203).

Pero también existía una justificación económica. Se debe hacer notar, que hacia 1850 en Costa Rica se había operado un cambio importante en la dirección tomada por el comercio que utilizaba la vertiente norte o caribeña. Dejó de usarse la ruta de Moín-Matina-Valle Central, para seguir la ruta Valle Central-Sarapiquí-San Juan Norte en los años 1851 a 1858 . Este cambio es evidente en el Cuadro 1 que muestra los ingresos por impuestos pagados en las aduanas del país durante dos décadas entre 1839 y 1858.

Cuadro 1. Impuestos pagados en las aduanas 1839-1858

\begin{tabular}{|c|c|c|c|c|}
\hline \multirow{2}{*}{ Año } & \multicolumn{3}{|c|}{$\begin{array}{c}\text { Ingresos de aduanas ma- } \\
\text { rítimas (en pesos) }\end{array}$} & \multicolumn{1}{|c|}{} \\
\cline { 2 - 4 } & $\begin{array}{c}\text { Del } \\
\text { Norte } \\
\text { (Ma- } \\
\text { tina) }\end{array}$ & $\begin{array}{c}\text { Del Nor- } \\
\text { te (Sara- } \\
\text { piquí) }\end{array}$ & $\begin{array}{c}\text { Del Sur (Pun- } \\
\text { tarenas) }\end{array}$ & \multirow{2}{*}{ Totales } \\
\hline 1839 & n.d. & & n.d. & 14,826 \\
\hline 1840 & 7,576 & & 19,217 & 26,793 \\
\hline 1841 & 15,404 & & 16,362 & 31,766 \\
\hline 1842 & 10,709 & & 17,364 & 28,073 \\
\hline 1843 & 15,631 & & 22,942 & 38,573 \\
\hline 1844 & 6,403 & & 40,313 & 46,716 \\
\hline 1845 & 5,676 & & 67,134 & 72,810 \\
\hline 1846 & 2,929 & & 50,803 & 53,732 \\
\hline 1847 & 1,109 & & 59,178 & 60,287 \\
\hline 1848 & 1,208 & & 42,589 & 43,797 \\
\hline 1849 & 47 & & 26,940 & 26,987 \\
\hline 1850 & & 5,000 & 54,396 & 59,396 \\
\hline 1851 & 2,633 & 57,054 & 59,687 \\
\hline 1852 & & n.d. & 74,599 \\
\hline
\end{tabular}

\begin{tabular}{|c|c|c|c|c|}
\hline 1853 & & 3,076 & 87,751 & 90,827 \\
\hline 1854 & & 7,671 & 112,998 & 120,669 \\
\hline 1855 & & 4,137 & 86,223 & 90,360 \\
\hline 1856 & & 4,527 & 115,174 & 119,701 \\
\hline 1857 & & & & 127,861 \\
\hline 1858 & & & & 111,833 \\
\hline 1859 & & & & 129,254 \\
\hline 1860 & & & & 139,163 \\
\hline 1861 & - & - & 191,140 & 191,140 \\
\hline
\end{tabular}

Fuentes: 1839-1860, Rico Aldave (2014), Cuadro Anexo 13; 1850 Memoria de Hacienda 1850-51, p. 17-18; 1861 Memoria de Hacienda 1861-62, p. 12-13.

Claramente Puntarenas en el Mar del Sur fue durante todo el periodo la aduana más importante del país, pero lo más notable fue el cambio de dirección ocurrido entre las dos aduanas del Mar del Norte. El cuadro muestra como de 1839 a 1849, el comercio (más que todo de importación) se realizó solo por Moín y Matina, mientras que, a partir de 1850 , dicho comercio comenzó a fluir solo por la ruta de Sarapiquí.

A partir de 1850, en las Memorias del Ministerio de Hacienda deja de mencionarse la aduana de Matina y más bien se hace referencia a la aduana de Sarapiquí, creada por Decreto 12 de octubre de 1850 y cuya sede en realidad estaba en la ciudad de San José y no en Sarapiquí. Una descripción de la aduana y sus funciones la presenta Belly (1858, p. 58).

Desafortunadamente los datos están incompletos para los años 1857-1860, para conocer cuál fue el desempeño de Sarapiquí en esos años, pero probablemente se redujo mucho la actividad y para 1861, la Memoria del Ministerio de Hacienda ya no indica ningún ingreso, por lo cual puede suponerse esta había dejado de operar. Varios fueron los factores que incidieran en su cierre, que nos limitamos a señalar: primero, que, con la Guerra Nacional y sus consecuencias, entre 1857 y 1860 la ruta del tránsito estuvo completamente clausurada; segundo, que la llegada de vapores a Puntarenas de manera cada vez más regular después de 1856, eliminó la necesidad de utilizar a San Juan Norte para el correo y pasaje; y tercero, que el mantenimiento de la ruta cesó. Acabó así la etapa inicial de la ruta de Sarapiquí, zona donde una muy poca y dispersa población se mantuvo con un proceso de colo- 
nización limitado, hasta entrado el siglo XX. Hacia 1858 en el bajo Sarapiquí solo quedaron 2 haciendas produciendo bananos, cacao y otros. Belly (1858). En el censo de 1864 no se registra población en Sarapiquí, y es hasta el censo de 1883, que se registran 243 habitantes en la "aldea de Sarapiquí".

\section{La Guerra Nacional y sus efectos sobre la Ruta al Norte}

Al surgir la crisis generada por la llegada de los filibusteros a Nicaragua en junio de 1855 y en particular con la declaración de guerra de Costa Rica al gobierno filibustero en febrero de 1856, las comunicaciones con San Juan del Norte fueron cortadas. Incluso la correspondencia oficial que se enviaba por correo por esa ruta a los representantes del país en el extranjero, fueron interceptadas y leídas por Walker. El país entonces enfrentaba una situación muy peligrosa en toda la frontera norte, pero particularmente en los dos tercios de ella hacia el este, donde prácticamente no tenía presencia física el Estado, a excepción del destacamento militar y la aduana en el Muelle de Sarapiquí.

Afortunadamente además de la ruta de Sarapiquí analizada en detalle anteriormente, e independiente de esta, estaba ocurriendo un fuerte movimiento colonizador en el Valle Central, dirigido en dirección oeste, el cual, al llegar a San Ramón, había comenzado a avanzar en una nueva dirección, hacia el norte. Esa nueva orientación fue hacia las llanuras de San Carlos, situadas más al oeste de las de Sarapiquí. Cuando el proceso de colonización llegó al extremo oeste del valle Central, a finales de la década de 1840, algunos de los colonizadores-emprendedores, buscaban nuevas tierras que denunciar, encontraron de San Ramón al norte, un paso en la cordillera por donde era posible bajar más cómodamente a las llanuras del norte, que por la vía de Sarapiquí. San Ramón se encuentra a $1.050 \mathrm{~m}$ de altura, y el paso se da a unos 1.100-1.200 $\mathrm{m}$ en las inmediaciones de las fuentes del río Barranca el cual toma al oeste para desembocar en el Pacífico, y de las fuentes del río Balsa que abren un valle hacia el norte, por donde pasaron los primeros colonos, y que hoy se utiliza para la carretera San Ramón-La Fortuna.

Una primera exploración salió en 1850 de San Ramón, liderado por Francisco Martínez con 10 acompañantes quienes, dirigidos hacia al norte en el cruce de un brazo del río Barranca, descendieron a las llanuras, llegaron al río San Carlos y bajaron por este hasta su desemboca- dura en el San Juan, hecho importante porque antes ningún costarricense había recorrido el curso alto del San Carlos. INDER (2015, cuadro 4) y Frantzius (1862, pp. 84-85). La ruta hacia San Carlos, a diferencia de la Sarapiquí atrajo a colonizadores quienes fueron mejorando el camino, de manera que cuando una compañía creada para construir el camino contrató un estudio sobre la ruta, se encontró que cerca de un tercio de esta ya permitía el tráfico de carretas, y con mulas se lograba llegar hasta El Muelle de San Carlos, von Bulow (1854, p. 10).

En 1851, el primer colonizador permanente se estableció en tierras de San Carlos. Victoriano Fernández Carrillo fue el nombre de este primer colono quien se ubicó en tierras de baldíos comprendidas entre Florencia y Terrón Colorado. Los siguientes colonos de los años 1850 en adelante se fueron estableciendo en Los Bajos, El Peje, Muelle, El Tanque y Arenal, INDER (2015, Cuadro 4); Quesada (1958, p. 3). El Censo de 1864 registra 627 habitantes en la zona San Carlos en ese año, mientras que, para el Censo de 1883, la población alcanzó a 1.613, y fueron haciendo denuncios de baldíos de manera lenta, pero cubriendo una gran extensión de tierras, la mayor parte de las cuales no fueron explotadas sino hasta entrado el siglo XX, pues muchos denuncios se hicieron con fines especulativos. En total entre 1849 y 1880 se realizaron 62 denuncios en la zona, con una extensión de unas 55.500 ha en total. En promedio cada denuncia fue de 895 ha, es decir una extensión mucho mayor de la cual esos colonos-denunciantes tenían capacidad de explotar racionalmente. Quintero (1984), cuadro 1.

En 1853-1854 la Sociedad Berlinesa de Colonización que a la sazón buscaba tierras para asentar a colonos de origen alemán en Costa Rica, según su contrato con el Gobierno, halló en San Carlos una posible zona para establecer una colonia. Por ello, el camino de Martínez (1850) fue seguido por Alejandro von Bulow, representante de la Sociedad en Costa Rica, quien partió de Grecia, no de San Ramón, llegó al primer brazo del río Barranca, antes de seguir la ruta de Martínez. Llegó hasta el río San Juan y publicó un informe y un mapa sobre el viaje, Frantzius (1862, pp. 84-85) y denunció una gran extensión de tierras entre el río San Carlos y el río San Juan, con la perspectiva de establecer una colonia alemana allí, pero la Guerra Nacional y la muerte de von Bulow durante ella, puso fin a esta iniciativa.

Iniciada la guerra contra Walker, esta en su primera fase fue orientada por el gobierno de Mora, hacia atacar y batir 
a los filibusteros en el Pacífico de Nicaragua, hacia allí se dirigió todo el esfuerzo bélico de la primera campaña, que luego de varias acciones -la mayoría favorables a las armas costarricenses-, culminó en Rivas en abril de 1856, pero cuando la epidemia de cólera se desató en el ejército, este debió retirarse y al volver al país, esparció el germen por todo el territorio, causando entre mayo y julio una enorme pérdida de vidas, estimada en cerca de un $10 \%$ de la población total. Fue solo meses después que se pudo retomar la guerra, y esta vez con una orientación diferente: la mayor parte del ejército fue dirigido al Pacífico nicaragüense como en la primera campaña, pero otra parte fue enviada a cortar la ruta del Tránsito, que era la principal vía de abastecimiento de hombres y armas de los filibusteros desde la costa este de los EE. UU. Para esta segunda fase, el control del río San Juan era vital, y desde el Valle Central, la forma de llegar a ese río era por medio de los ríos Sarapiquí y San Carlos.

\section{La Campaña del Tránsito}

Con este nombre, se conocen el conjunto de hechos que llevaron al ejército de Costa Rica a atravesar la cordillera que limita por el norte al Valle Central y cruzar las llanuras del norte para llegar al río San Juan, cortando así el suministro de refuerzos a los filibusteros provenientes de EE. UU. Como los filibusteros ya habían cortado la comunicación al capturar el punto en el cual el río Sarapiquí desemboca en el San Juan, conocido en Costa Rica como La Trinidad y como Hipps Point por los estadounidenses. En esta situación y necesitando el Gobierno de información sobre una manera de acceder rápidamente a la Vía del Tránsito, envió en noviembre al Coronel Pío Alvarado a hacer un reconocimiento de la zona norte hasta el río San Juan. Este lo hizo partiendo de San Ramón por el camino existente hasta El Muelle, allí se embarcaron en botes hasta la desembocadura del río Arenal, de donde por tierra tomaron en dirección noroeste, cruzando llanuras y colinas y luego de nuevo llanuras todas cubiertas de bosque denso y encontrando población indígena (Guatusos), hasta el llegar al río Frío. Bajaron por este hasta su desembocadura en el Lago de Nicaragua, muy próximo a donde sale el río San Juan, sitio que se encuentra al frente del fuerte de San Carlos, que era punto clave de control del río, entonces en manos de los filibusteros. Cumplido el reconocimiento militar Alvarado estimó la distancia entre el punto de desembarque en el río Arenal y la boca del río Frío en unas ocho y media leguas y él y sus acompañantes regresaron por el mismo camino, Obregón (1956, pp. 237-241). El 16 de diciembre durante su regre- so aguas arriba por el San Carlos, se encontraron con una segunda expedición, esta vez formada por una división de vanguardia al mando del mayor Máximo Blanco y el coronel Barillier, enviada por el río para capturar los barcos de vapor de la Compañía Accesoria del Tránsito. Boletín Oficial, 17 de diciembre (1856, p. 565). Estas naves estaban sirviendo a los filibusteros contra Costa Rica, al haber Walker confabulado con Morgan y Garrison, dos de los directores de la empresa madre de la CAT, para quitar la concesión a Vanderbilt que se encontraba fuera de los EE. UU. y traspasar a sus ex socios.

Para frenar el uso de la vía del Tránsito, Costa Rica desde octubre tomó la decisión de capturar la vía del Tránsito, iniciada con una declaratoria de bloqueo de San Juan Norte y de prohibición de la navegación por el río, Obregón (1956, pp. 243-244). A mediados de diciembre 1856 una fuerza militar fue organizada y enviada para tomar el Tránsito, al mando del general José Joaquín Mora y el mayor Máximo Blanco, la cual tomó una ruta que partía de San José con paso por Alajuela, y de allí continuó al Muelle del San Carlos vía Grecia, La Laguna, Los Mancos y el río Peje. El trayecto hasta El Muelle lo completaron en 5 días y luego se construyeron balsas para que parte de la tropa, comandada por el mayor Blanco, descendiera por el río hasta el San Juan, donde en el transcurso de 20 cortos días tomó exitosamente todos los vapores del Tránsito, Obregón (1956, pp. 252-257), describe los detalles de la toma de los vapores, uno de los triunfos más importantes del ejército, y sin duda el de mayor valor estratégico de toda la campaña. Uno de los hechos bélicos más señalados fue la derrota del destacamento filibustero en La Trinidad, que fue tomado por sorpresa por las tropas costarricenses que descendieron por el río San Juan hasta la desembocadura del Sarapiquí, destacó en esta acción el sargento Nicolás Murillo Aguilar. Estas diversas acciones se muestran en la figura 3, donde se señalan con letras los puntos álgidos de las acciones y movimientos (flechas en azul) del ejército costarricense, que se enumeran en el mismo mapa.

Tomado el Tránsito, uno de los vapores, el Bulwer ascendió por el río San Carlos para llevar al cuerpo principal del ejército que lo esperaba en El Muelle y conducirlo hasta el río San Juan, con el propósito de ocupar el Castillo y el fuerte de San Carlos, y así obtener el control total del río, desde la boca del Sarapiquí hasta el Lago de Nicaragua. Obregón (1956, p. 275). Un contra ataque de los filibusteros resultó en la recuperación por estos de algunos vapores y con ellos retomaron parte del río, pero 
no lograron desplazar a los costarricenses del dominio del río, y este nunca más pudo ser utilizado para traer refuerzos filibusteros desde los EE. UU. Con ello se pudo aprovechar de nuevo la ruta de Sarapiquí para aprovisionar a las tropas desplazadas sobre ese río.

El abastecimiento de las tropas asignadas a defender el río San Juan fue una labor problemática, porque en la región de San Carlos y Sarapiquí, escaseaban los alimentos principales (maíz, frijoles, carne) que necesitaban las tropas; solo plátanos y yuca se encontraban en la zona; el resto era necesario conducirlo desde el Valle Central. Así se hacían publicaciones pidiendo ganado y otros víveres para abastecer al ejército, como se ve en el siguiente aviso.

"Aviso. Se necesitan 50 bueyes gordos para el abasto del ejército. -Los ganaderos que quieran venderlos pueden acudir a la Proveduría Jeneral [sic] para el ajuste, pagándoles al contado". Boletín Oficial, diciembre 17, (1856, p. 565).

Las dificultades para conducir los abastos hasta las tropas en San Carlos se reflejan muy bien en el comunicado siguiente enviado desde el ejército en San Carlos:

Correo de San Carlos. El 15 habrá bajado el río la primera división para posesionarse del San Juan. - La segunda marchaba en buen órden y completa salubridad. -El camino es intransitable. -Dos compañías numerosas se ocupan de mejorarlo con suma actividad. Quinientos hombres ha sido necesario emplear para el transporte de víveres y pertrechos, existiendo ahora en esa ruta y sobre el río más de 2000 personas. -Aguardamos muy pronto un suceso importante y muy trascendental. - La línea del tránsito es el todo de los filibusteros. Boletín Oficial, diciembre 20, (1856, p. 570).

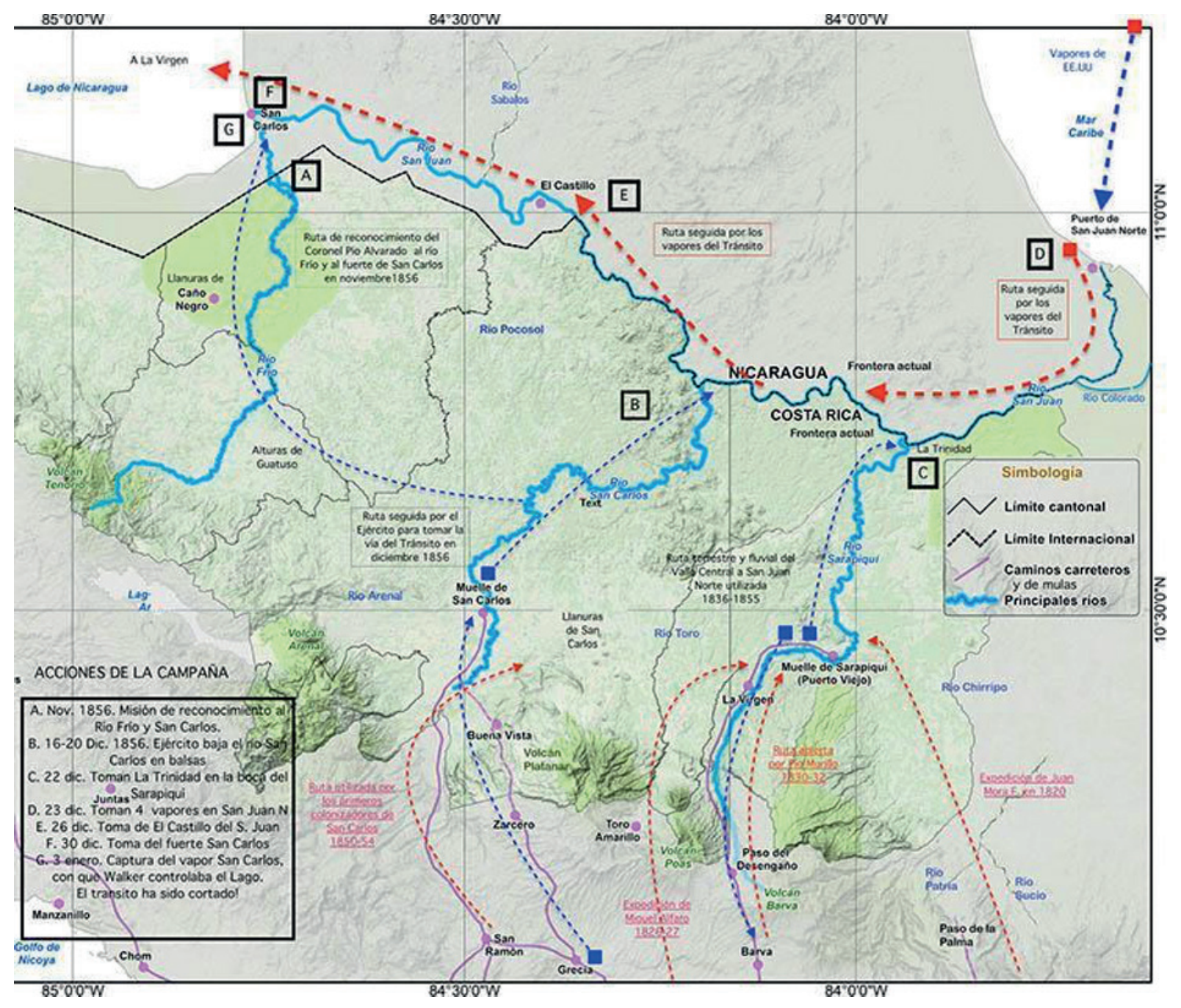

Figura 3. La campaña en el río San Juan noviembre 1856 a enero 1857. Fuente: Elaboración propia sobre la base de un mapa en León y Mora Proyecto 806-B6-205. 
Como se denota en el comunicado anterior, los caminos eran difíciles, puesto que todavía llovía en la parte alta del paso de la cordillera, esto en especial afectó el paso de las tropas por la vereda a San Carlos, a pesar de los esfuerzos del Gobierno por hacerla pasable hasta El Muelle. El primer contingente de tropa a cargo de Máximo Blanco tomó 5 días en recorrer el trayecto de Grecia a El Muelle, donde llegó el 9 de diciembre. El diario del comandante muestra la dificultad de realizar la logística para mantener abastecidas a las tropas, al inicio de la campaña del Tránsito, en una ruta parcialmente completa a San Carlos. Desde que salió de Grecia, debido a la marcha forzada de los soldados, se dieron problemas para que las provisiones y el parque -llevadas presumiblemente en mulas - siguieran a estos al mismo ritmo, y así poder alimentar a las cansadas tropas al final de cada jornada, Blanco (1939, p. 411). Por esto, es que existe un viejo dicho: ¡los ejércitos avanzan con su estómago! Sin alimentación y pólvora no se podía proceder. Una vez llegados a El Muelle de San Carlos, Blanco se encontró también con que los botes que se iban a fabricar para bajar por el río hasta el San Juan no estaban listos y no estarían listos sino en un mes. Aunque un oficial actuaba como proveedor, no fue sino hasta varios días después el día 13 que llegó al Muelle, don Francisco González en el cargo de "comandante del camino (y)...proveedor".

Se tomaron previsiones para enfrentar el clima y el río, fabricaron en el sitio con hule extraído de árboles del bosque, cobertores para las tapallaves de los mosquetes y rifles con que venían armados los soldados, con la finalidad de protegerlos de la lluvia para evitar que se mojara la pólvora. Con los pocos botes y balsas disponibles el 16 empezó el contingente a bajar por el San Carlos, pero la falta de bogas experimentados hizo que fuera lentamente y perdieron un bote con mucho de las provisiones y el parque, y luego la balsa en que llevaban los cañones se soltó y se perdió río abajo. Blanco (1939, p. 411-412) da a entender que González como comandante del camino, le correspondía no solo mover las provisiones del ejército, sino además asegurar que el camino estuviera en condiciones de permitir ese movimiento. La balsa con la artillería afortunadamente pudo recuperarse unos días después en el San Juan, gracias a que un nicaragüense la ocultó.

La captura del puesto de La Trinidad el 22 de diciembre y de los vapores del río en San Juan Norte al día siguiente permitieron culminar con éxito esta fase de la campaña, pero el sistema de suministro de provisiones continuó siendo un punto flaco en los meses siguientes, porque las grandes distancias del Valle Central hasta el río San Juan impidieron un flujo constante de alimentos y municiones.

En el diario Blanco muestra cómo eran de escasas las provisiones, obligaba al ejército a aprovechar las que encontraban en los vapores capturados, por ejemplo, la captura del vapor La Virgen, del cual se tomó mucho armamento o de botes provenientes de Granada con víveres, se complementaba con compras a los habitantes del río y del lago, Blanco (1939, pp. 419-421). Comerciantes nacionales también se arriesgaron a llevar algunas provisiones al ejército en el San Juan, pero la limitación era que los soldados y oficiales contaban con poco dinero para comprar, Blanco (1939, pp. 425-427) menciona a un comerciante de Alajuela, Crisanto Soto quien llevó a La Trinidad diversos alimentos, siendo necesario fijar los precios a los productos, para que no se abusara del hambre de los soldados.

Otras crónicas de la campaña como el "Diario de un oficial del ejército", publicado en el Boletín Oficial entre diciembre 1856 y marzo de 1857 y los "Pasajes de la historia de Costa Rica" del Pbro. Rafael Brenes, quien acompañó como capellán al ejército, confirman como las grandes distancias, el territorio despoblado y los malos caminos incidieron sobre los problemas de abastecimiento y esto repercutió en varias ocasiones la moral de las tropas, pese a lo cual se logró culminar la campaña con éxito. Brenes, por ejemplo, indica cómo a pesar de las medidas tomadas por el gobierno para prever las necesidades de los soldados, la realidad del ambiente físico de la zona de guerra a menudo frustraba estas intenciones. Este por ejemplo escribía:

Desde la salida del ejército de San José, ...en el tránsito hasta San Carlos, no hubo la menor queja de un solo individuo... (se) supo arreglar perfectamente bien el descanso de sus soldados en los campamentos de Alajuela, Grecia, Laguna, Mancos, Peje y San Carlos, a pesar de las fuertes lluvias. Con anticipación el Gobierno había mandado a don Francisco Alvarado Mora a fabricar embarcaciones que formaban la flotilla con que el mayor Blanco fuese a acometer tan peligrosa como atrevida empresa. ¡Qué embarcaciones! Trozos de gruesos garrotes labrado a golpe de hacha y machete y unas improvisadas balsas formaban nuestros navíos de guerra, Marinos ninguno: el único marino ... era don Francisco Alvarado...(Brenes en Korte 2017, p. 85). 
Una actividad importante que continuó realizándose a pesar de los problemas señalados, fue la del correo internacional del país, el cual continuó partiendo de San José por la vía del Sarapiquí hasta el puerto de San Juan Norte y viceversa. Al tomar el control de los vapores los costarricenses en enero de 1857, permitió asegurar las comunicaciones entre el teatro de guerra y el Gobierno en San José, como lo atestigua la frecuencia con que las crónicas anteriores hacen referencia al paso de correos oficiales por Sarapiquí.

\section{La ruta al norte y la definición de la frontera}

Los caminos rústicos explorados a lo largo del periodo 1820-1855, fueron uno de los factores que permitieron al ejército tomar la vía de la Compañía Accesoria del Tránsito a finales del año 1856, y continuar controlando esa durante los siguientes meses hasta junio de 1858, cuando regresaron la mayor parte de las tropas desplegadas en el río San Juan. El retiro del ejército se hizo como resultado de la ratificación del Tratado de límites Costa Rica-Nicaragua, conocido como Tratado Cañas-Jerez, el cual además de fijar las fronteras obligaba a Costa Rica a entregar las posiciones que sostenía en el río San Juan como el fuerte de San Carlos, punto clave de la ruta del Tránsito. A cambio de retirarse de la ruta del Tránsito, el país obtuvo de Nicaragua este acuerdo de una línea fronteriza favorable, una que 10 años antes había sido negociada entre ambos países, pero que entonces no fue ratificada por Nicaragua, Obregón (1993, pp. 230-231). En 1848 las negociaciones fueron llevadas por Felipe Molina por Costa Rica y el mismo Máximo Jerez, quien una década más tarde firmaría el tratado definitivo por Nicaragua. Un amplio estudio de esas negociaciones puede ver se en Obregón (1984, capítulo III).

Existió confusión en ambos países, sobre cómo proceder en restablecer relaciones normales en el periodo inmediato a la eliminación de los filibusteros, pues cada uno trató de aprovechar en su beneficio propuestas de canalización del río San Juan y el Lago, presentadas por especuladores extranjeros. En el caso de Nicaragua, había negociado en junio de 1848 un acuerdo (Cass-Irrisarri) con el Gobierno de los EE. UU. para devolver la ruta a la Compañía Accesoria del Tránsito o su sucesora estadounidense. Por su parte Costa Rica cometió el error de negociar el contrato Webster-Mora, cuando el presidente Mora se dejó influenciar por William Webster, un especulador inglés que desde 1856 intentaba obtener un contrato para construir un posible canal interoceánico, Obregón (1993, pp. 232-234). Mayores detalles pueden verse en Woodbridge (1967).

Las relaciones entre los dos países se volvieron muy conflictivas, Nicaragua incluso declaró la guerra, hasta que prevaleció la cordura y se negoció el Tratado Cañas-Jerez, donde cada una de las partes cedió en sus reclamos para llegar a un acuerdo.

El tratado de límites fue mal recibido por sectores en los dos países, pero es el mismo que rige hasta el presente. La posición de fuerza de Costa Rica al tener el control del río San Juan pesó sin duda en que Nicaragua aceptara los límites que 10 años antes había rechazado. Uno de los cambios que aceptó esta última fue relacionado precisamente con el territorio abierto por las dos rutas al Norte, la de Sarapiquí y la de San Carlos. Antes del tratado Nicaragua reclamaba ese territorio, pero este quedó dentro de los límites de Costa Rica. Costa Rica obtuvo además posesión hasta la margen sur del río San Juan, desde San Juan Norte hasta casi El Castillo, sobre la que antes de la Campaña Nacional no tenía posesión, y aunque aceptó una línea de unos 3 kilómetros al sur del Lago de Nicaragua y no sobre la orilla del lago mismo, aún esto era una gran mejora sobre sus posiciones territoriales anteriores.

Si bien Nicaragua obtuvo de vuelta su dominio sobre la ruta del Tránsito, fue hasta 1862 que volvió a funcionar, para lo cual fue necesario adquirir nuevos vapores, pues la mayoría de los originales habían sido destruidos durante la guerra o en accidentes. La vida de esta segunda ruta del tránsito fue corta, debido a que cuando se concluyó el ferrocarril transcontinental en EE. UU. en 1869, los pasajeros que la utilizaban prefirieron este nuevo medio que recortaba considerablemente el trayecto, Folkman (1993, p. 166), razón por lo cual la ruta de Nicaragua entró en olvido hasta unos años después cuando resurgió la posibilidad de un canal interoceánico, León y Arroyo (n.p. Capítulos XI y XII).

\section{Resultados de la apertura de la ruta al Norte}

En las secciones anteriores se mostró el medio geográfico en el cual se ubicaron las rutas al Norte y como se desarrolló el proceso histórico de apertura de estas entre 1820 y 1860 aproximadamente. De los diversos aspectos analizados se destacan los siguientes como hechos más relevantes. 
El descubrimiento de rutas al Norte entre 1820-1833, por exploradores privados incentivados por el Estado, permitió establecer una ruta mixta de bestias y botes al río Sarapiquí para conducir a viajeros, comercio y correo al Mar del Norte que operó entre 1830-1860, la cual a partir de 1850 sustituyó al viejo camino al Caribe vía Moín y Matina y ello llevó a establecer una aduana en El Muelle de Sarapiquí que estuvo activa por unos diez años a partir de 1850. La expansión del proceso de colonización por la parte oeste del Valle Central (San Ramón y Grecia) condujo a la apertura de una segunda ruta al norte, utilizando el río San Carlos.

La existencia de esas vías al Norte, compuestas de veredas precarias y de ríos navegables, fueron vitales para que durante la Campaña Nacional, Costa Rica pudiera cerrar la ruta del Tránsito, la arteria principal de abastecimiento de los filibusteros. Al estar ocupada por los filibusteros la boca del río Sarapiquí en La Trinidad, el ejército, al decidir que la segunda campaña incluiría la toma del Tránsito, fue obligado a utilizar como ruta alterna la del río San Carlos. Esto tomó por sorpresa a los filibusteros y se logró una importante victoria en La Trinidad que se completó con la captura de todos los vapores en el río y en el lago. La guerra se ganó porque fue posible para Costa Rica desplegar su ejército hasta el río San Juan y darle el apoyo logístico requerido hasta la rendición de Walker en junio de 1857 y aún por un año adicional.

Con la ocupación por Costa Rica de la ruta del Tránsito, se dieron las condiciones para negociar con Nicaragua el establecimiento de la frontera definitiva mediante el Tratado Cañas-Jerez. Las posiciones tomadas y los vapores fueron devueltos a Nicaragua a la firma de este. Aunque en el país surgieron reclamos por la devolución de la ruta del Tránsito, es claro que hubiera sido imposible para Costa Rica mantener ocupada esta, dadas las grandes distancias del Valle Central y la dificultad y costo de mantener abastecido al ejército, además de que la situación económica al final de la campaña era crítica para el país. La campaña de la ruta del Tránsito generó en décadas posteriores en ambos países, un mayor interés sobre los derechos de cada cual, para el caso de la apertura de un canal, hecho que fue alimentado por las políticas ejercidas por las grandes potencias sobre Centroamérica.

La apertura de la vía por San Carlos fue de gran significación posterior para el país, pues los soldados que tomaron esa ruta conocieron las riquezas de suelos y aguas de las extensas llanuras del norte, lo cual indujo a algunos de es- tos a buscar colonizar la zona en décadas posteriores, así inició el proceso de integración de esa extensa región a la economía nacional. En cambio, la ruta por Sarapiquí quedó relegada como vía de comunicación durante el último tercio del siglo XIX, y no fue sino hasta entrado el siglo $\mathrm{XX}$, cuando fue reabierto el camino a esa zona, iniciando así la colonización de la parte oriental de la región norte.

\section{Referencias}

Aguirre, F. (2002). Un atlas histórico de Nicaragua. Managua, Nicaragua. Fundación Vida.

Anónimo. (1914). Documentos relativos a la Guerra Nacional de 1856 y 1857 con sus antecedentes. Tomo I. San José, Costa Rica. Tipografía Nacional.

Archivo Nacional de Costa Rica (ANCR) (Varios años). Fondo Fomento, número 1673, 1681, 1683, 3617, 3888; Fondo Hacienda, número 6658, 9326, 17469. 24996.

Arellano, J. comp. (2005). Nicaragua en el siglo XIX. Testimonio de funcionarios, diplomáticos y viajeros. Managua, Nicaragua. Fundación Uno.

Baily, J. (1848). Apuntamientos sobre el Lago de Nicaragua, el Río San Juan y el istmo situado entre el Lago y el Océano Pacífico. En Arellano (2005), pp. 93-106.

Belly, F. (1858). El Istmo Americano. En: Zeledón (1997), Viajes por la República de Costa Rica, Tomo I.

Blanco, M. (1939). Diario que llevó el sargento mayor don Máximo Blanco en la expedición al río San Juan por la vía de San Carlos - años de 18561857. Revista de los Archivos Nacionales. III (78), pp. 409-432.

Brenes, R. Crónica del Padre Rafael Brenes. En: Korte (2017).

Cooper, E. (1896). Informe sobre el camino a Matina y la costa norte presentado por don Enrique Cooper el año de 1838. (2. ${ }^{a}$ edición). San José, Costa Rica. Tipografía Nacional.

Folkman, D. (1993). La ruta de Nicaragua. Managua, Nicaragua. Fondo de Promoción Cultural BANIC. 
Frantzius, A. von (1862). La ribera derecha del río San Juan. En: Zeledón (1997), Viajes por la República de Costa Rica, Tomo 2.

Girot, P. (1989). Formación y estructuración de una frontera viva: El caso de la Región Norte de Costa Rica. Geoistmo. III (2).

Gobierno de Costa Rica, Colección de Leyes, Órdenes y Decretos (CLOD). Varios años. San José, Costa Rica.

Gobierno de Costa Rica, Secretaría de Hacienda, Memoria 1861-1862. San José, Costa Rica.

González, M. (1823). Bosquejo político estadístico de Nicaragua formado en 1823. En Arellano (2005), pp. 15-38.

González, P. (1976). Ruta de Sarapiquí. Historia socio-política de un camino. Instituto de Investigaciones Sociales, Avances de Investigación No. 15.

Haefkens, J, (1832). Viaje a Guatemala y Centroamérica. En Arellano (2005), pp. 39-62.

INDER (2015). Informe de caracterización básica, Territorio San Carlos-Peñas Blancas-Río Cuarto. San Carlos, Costa Rica. Instituto de Desarrollo Rural de Costa Rica.

Korte, W. (2017). Los diarios de la Campaña del Tránsito y la otra cara de la moneda. Introducción, traducción, transcripción y estudio. San José, Costa Rica. EUNED.

León, J. (1997). Evolución del comercio exterior y del transporte marítimo de Costa Rica 1821-1900. San José, Costa Rica. Editorial de la Universidad de Costa Rica.

León, J. y Mora, D. (2018). “Desarrollo de un espacio económico y su conformación en la región Norte de Costa Rica"; en: Reconstruyendo espacios y regiones en Centroamérica siglos XIX-XXI. Informe final. Proyecto VI-UCR 806-B-205. San José, Costa Rica. UCR-CIHAC.

León, J. y Arroyo, N. (n.p.). Transportes y Comunicaciones en el desarrollo económica de Costa Rica, Tomo V Historia Económica de Costa Rica en el siglo XX. En vías de publicación.

Molina, F. (1851). Bosquejo de la República de Costa Rica. Nueva York, EE.UU. Imprenta de Benedict.
Obregón, R. (1956). La Campaña del Tránsito 18561857. San José, Costa Rica. Antonio Lehmann.

Obregón, C. (1984). Costa Rica. Relaciones exteriores de una república en formación. San José, Costa Rica. Editorial Costa Rica.

Obregón, C. (1993). El río San Juan en la lucha de las potencias 1821-1860. San José, Costa Rica. EUNED.

OEA (2004). Cuenca del San Juan. Análisis de diagnóstico transfronterizo. http://www.oas.org/sanjuan/ spanish/documentos/adt/introduccion.html

Quesada, Fenelón (1958). Monografía de San Carlos. San José, Costa Rica. Imprenta Falco.

Quintero, A. (1984). Características del proceso de apropiación de baldíos en la región de San Carlos 1850-1910. Tesis. UNA, Heredia, Costa Rica.

Rico-Aldave, J. (2014). La Renta del tabaco en Costa Rica (1766-1860). San José, Costa Rica. EUNED.

Roberts, O. (1965). Narratives of voyages and excursions on the East coast and Interior of Central America. Gainsville. University of Florida Press.

Robertson, R. (1964). History of the American Economy. Nueva York., EE.UU. Harcourt Brace \& World.

Sáenz, A. (1970). Historia Agrícola de Costa Rica. San José, Costa Rica. Editorial de la Universidad de Costa Rica.

Seija-Riitta, Laakso (2006). Across the Oceans. Development of Overseas Business Information Transmission, 1815-1875. Thesis, University of Helsinski. Helsinski.

Trevithick, F. (1871). Life of Richard Trevithik with an account of his inventions. Londres, Inglaterra. E \& F.N. Spon Tomo I.

Von Bulow, A. (1849). Die Wichtiokeit von Nicaragua fur die Colonisation. Berlin. Gustav Hemple.

Von Bulow, A. (1854). Informe sobre el camino y la navegaciòn del río San Carlos. San José, Costa Rica Imprenta de la Paz.

Woodbridge, Paul (1967). Los contratos Webster-Mora. San José, Costa Rica. Lehmann. 


\section{Yulpok}

Zelaya, Ch. (1971). El Bachiller Osejo, Tomo II. San José, Costa Rica. Editorial Costa Rica.

Zeledón, E. (1997). Viajes por la República de Costa Rica Tomo 2. San José, Costa Rica. MCJD, Dirección de Publicaciones. 